\title{
The role of perceived distance in determining apparent visual size
}

\author{
LEONARD BROSGOLE, THOMAS J. PlaHOVINSAK, MIGUEL ROIG, \\ and JOSEPH P. NOTARO \\ St. John's University, Jamaica, New York
}

\begin{abstract}
Subjects viewed visual stimuli in total darkness and estimated their sizes and distances with several cues to distance varied. The introduction of distance cues generally was found to have a primary effect upon the perception of distance, with a relatively slight effect upon the perception of apparent size. The question was raised as to why the available cues to distance were not taken into account in estimating size, and it was suggested that perhaps perceived distance is not involved in determining phenomenal size.
\end{abstract}

Gregory and Ross (1964a) found that passively moving subjects made underconstancy matches when monocularly viewing and estimating the size of a stationary visual target in darkness. Although an improvement was found in the estimation of size with binocular vision and proprioceptive feedback to bodily movement, the obtained size estimates still varied as a function of distance and were lower than what would be expected on the basis of visual angle (Gregory \& Ross, 1964b). Brosgole, McNichol, Doyle, and Neylon (1976) found similar results when stationary subjects judged the size of a visual stimulus which moved toward and away from them in total darkness.

The above-mentioned studies raise questions as to why there was a failure of size constancy with a dynamic change in the distance between the observer and a visual stimulus. It was reasoned that perhaps movement impaired the subjects' abilities to take distance into account for purposes of estimating size by reducing the valuable time needed for combining information regarding distance and visual angle. Accordingly, this study was aimed initially at determining the effect of varying the length of exposure to a stimulus on the perception of its size and distance. It was felt that size perception should have regressed toward visual angle with very brief stimulus exposures due to the insufficiency of the time allowed for taking distance into account. While in progress, the scope of the study was expanded to address the more general question of the nature of the relationship between apparent size and perceived distance.

The aim of this study was to determine whether those factors that affect the perception of distance influence perceived size in equal measure. In order to accomplish our purpose, four factors were manipulated which were expected to have an impact upon the perception of distance.

Correspondence should be addressed to L. Brosgole, Psychology Laboratory, St. John's University, Grand Central Station and Utopia Parkways, Jamaica, NY 11439.
Size and distance estimates were obtained in total darkness for each of these manipulations by having the subjects adjust a comparison stimulus after viewing a standard stimulus. The first factor involved varying the condition of viewing, that is, monocular versus binocular regard. The second variation was concerned with changing the distance of the standard stimulus with regard to the subject. The third dealt with varying the location of the standard stimulus with reference to the objective eye-level position of the observer. Thus, half of the subjects viewed the standards centered at eye level, and half saw the standards placed just above the floor of the testing chamber. It was felt that by lowering the standards, the subjects would see them rising upward with increasing distance and that this perspective effect would serve as a potent perceptual cue to distance. The fourth and final manipulation involved varying the duration of stimulus exposure. Thus, the standards were presented for $25 \mathrm{msec}$ to half of the subjects and for $2,000 \mathrm{msec}$ to the other half. It was felt that the brief exposure of the standards would reduce the available cues to distance by minimizing reflectances from surrounding surfaces and by eliminating the opportunity to scan the environment. In this study, we attempted to determine whether our experimental manipulations generated changes in perceived distance that were paralleled by changes in apparent size. Thus, we directly addressed the issue as to whether or not apparent size is dependent upon perceived distance exclusively, as suggested by the invariance hypothesis.

\section{METHOD}

\section{Subjects \\ Thirty-two males and 48 females participated in this study. Their ages ranged from 17 to 40 years, with a mean age of 20.8 years. They were all undergraduate students who were naive as to the purpose of the study.}

\footnotetext{
Apparatus

The equipment consisted of four standard and two comparison stimuli. One of the comparisons was used for estimating the sizes of the standards, and the other for judging their distances. All of the stimuli were made of Sylvania white electroluminescent Tape-Lite, which was
} 
powered by variable ac transformers set at 30 volts. Five raters independently judged all of the stimuli to be of equal brightness and color and barely discriminable when presented for $25 \mathrm{msec}$ in total darkness.

The standard stimuli were created by mounting strips of Tape-Lite vertically on upright wooden stands. The stands were secured to the floor along the long arm of an L-shaped darkroom 5, 10, 15, and $20 \mathrm{ft}$ from the observers. The standards could not all be aligned directly within the subjects' line of regard, for the nearer stimuli would have then partially occluded the more distant ones. Therefore, the farthest standard was positioned directly ahead, and the one $15 \mathrm{ft}$ away was 6 in. off to its left. The 10-ft-distant standard was 3 in. to the right of center, and the 5-ft-distant stimulus was 2 in. to the right. The stimuli were 6.29 , $12.58,18.87$, and 25.16 in. high, from nearest to farthest. Thus, the heights of the standards varied proportionately with distance, as did their widths (the 5 -ft-distant stimulus was .25 in. wide). When centered with respect to the subject's eye-level position, each standard stimulus subtended a visual angle of $6^{\circ}$ vertically, $3^{\circ}$ above and $3^{\circ}$ below eye level.

The size-comparison stimulus was located $5 \mathrm{ft}$ to the observers' right, along the short arm of the $\mathrm{L}$. It consisted of a vertical strip of Tape-Lite (.25 in. wide) which could be lengthened or shortened symmetrically about the center. The middle of the strip was coincident with the subject's eye-level position. The adjustment of the comparison was measured to the nearest eighth of an inch. The distance-comparison stimulus consisted of a horizontal length of Tape-Lite that was 35 in. long and .25 in. wide. It was located $5 \mathrm{ft}$ to the subjects' left and was centered with regard to the eye-level position. A masking panel that could slide from side to side was placed in front of the stimulus, allowing it to be lengthened or shortened. The distance estimates were measured to the nearest eighth of an inch. In order to promote a reliable estimation of the distance of the standards, a reference stimulus was added just above the comparison. This consisted of a 5 -in. horizontal length of Tape-Lite that was $.25 \mathrm{in}$. wide. The subjects were told that the length of the reference stimulus represented a distance of $5 \mathrm{ft}$ (i.e., the distance estimates were to be scaled down by a factor of 12), and that they were to judge how far away each standard was by varying the comparison in proportion to the reference. The reference was presented prior to the adjustments and was shut off before the estimates were made.

All surfaces surrounding the stimuli were painted flat black to minimize reflectances. Both stimulus duration and the order for presenting the standards were varied by a program composed of BRS (Series 200 and 400) logic modules. Each trial was initiated by depressing a trigger switch, which resulted in the lighting of a standard stimulus after a 1sec delay. The switch closure produced an audible click which provided the subject with a warning or ready signal. The subject's head was positioned in a Bausch \& Lomb chinrest which was mounted on a Bausch $\&$ Lomb instrument table. A plastic dowel, 8 in. long $\times .5$ in. in diameter, was mounted vertically on the instrument table in front of the chinrest. The dowel was coincident with the subject's objective median plane. The subjects were instructed to grasp the tip of the dowel with the thumb and index finger of their preferred hand and to hold their eyes level while maintaining their gaze in the direction of the felt position of their fingertips. In this way, they were able to fixate appropriately in total darkness, prior to the presentation of a standard stimulus. A metal shield, which could be pivoted to cover the subject's nonpreferred eye, was placed on the instrument table. This was used during the monocular conditions when the standards were viewed with the preferred eye, but the comparisons were adjusted using binocular vision. The use of the shield eliminated the need for disturbing patches.

\section{Procedure}

There were eight conditions, with 10 different subjects in each. The standard stimuli were presented to half of the subjects for $25 \mathrm{msec}$ and to half for $2,000 \mathrm{msec}$. In addition, the standards were centered at about eye level for half of the subjects and exposed below eye level (i.e., 18 in. above the floor) to the other half. Finally, half of the subjects viewed the standards monocularly, and half viewed them binocularly. In combination, these three manipulations gave rise to eight conditions. The subjects provided both size and distance estimates for all four standards within each treatment. Each subject generated 32 size estimates, 8 for each standard. The order of presenting the standards was counterbalanced over trials and subjects. The same case held for the distance estimates, for a total of 64 trials. The size and distance judgments were made in blocks of 32 trials each. Half of the subjects within each treatment made their size estimates first, and half made their distance judgments first. The comparison stimuli were adjusted by the experimenter at the instruction of the subject in counterbalanced ascending and descending order. Although the exposure of the standards was timed, the adjustment of the comparisons was not. However, the subjects were not able to look back and forth between the standard stimulus and the comparison stimulus.

The experiment took place in total darkness. The subjects were led into the darkroom blindfolded and seated on a swivel chair by the instrument table. They were permitted to dark-adapt for $7 \mathrm{~min}$. They were given "objective" size and distance instructions and were encouraged to report their phenomenal experience during the intertrial intervals.

\section{RESULTS AND DISCUSSION}

The size and distance data, which were recorded in inches, were converted separately into proportions. That is to say, each subject's mean estimates for the 5-ft-distant standard stimulus were assigned a value of 1.0 . The data for the 10-, 15-, and 20-ft standards were then referenced to the estimates for the 5 - $\mathrm{ft}$ stimulus and expressed as a proportion of those estimates. Thus, if a subject judged the 5 -ft-distant standard to be $5 \mathrm{in}$. high and the $10-\mathrm{ft}$ distant standard to be 7.5 in. high, then those data would be converted to read 1.0 and 1.5. (Of course, they should have been 1.0 and 2.0, if the subjects were perceiving size veridically.) The same procedure was used for the distance estimates. By use of such proportions, the size and distance judgments were converted into common terms. This enabled those distinctively different sets of data to be incorporated into a single analysis of variance as two levels of one factor (type of estimate) and allowed us to see whether or not this factor interacted significantly with the others contained in the analysis. The presence of any significant interaction involving "type of estimate", would certainly indicate that apparent size is not linearly related to perceived distance, and might even raise questions as to the extent to which the appreciation of distance is necessary for determining phenomenal size.

The data were subjected to a $2 \times 2 \times 2 \times 2 \times 4$ splitplot factorial analysis of variance. There were three between-subject factors, namely, "condition of viewing" (monocular vs. binocular), "target position" (at vs. below eye level) and "stimulus duration" (25 vs. $2,000 \mathrm{msec}$ ). There were two within-subject factors, namely, "type of estimate" (size vs. distance) and "distance of the standard stimulus" $(5,10,15$, and $20 \mathrm{ft})$. The analysis produced two significant interactions. The first was a significant four-way interaction which included every factor except stimulus duration $[\mathrm{F}(3,216)=3.31$, $p<.05]$. The second consisted of a significant two-way interaction of stimulus duration $\times$ distance of the standard $[F(3,216)=5.50, p<.01]$. We will consider the higher order interaction first. Refer to Table 1 for the means contained in that interaction.

The four-way interaction was evaluated throughout by the use of "simple effects." The simple effects revealed 
Table 1

A Summary of the Mean Proportions Contributing to the Obtained Four-Way Interaction

Distance of the Standard Stimuli

Type of Response $\begin{array}{llll}5 \mathrm{ft} & 10 \mathrm{ft} & 15 \mathrm{ft} & 20 \mathrm{ft}\end{array}$

\begin{tabular}{|c|c|c|c|c|c|}
\hline \multicolumn{6}{|c|}{ Monocular Observation } \\
\hline $\begin{array}{l}\text { Standards Centered } \\
\text { at Eye Level }\end{array}$ & $\begin{array}{l}\text { Size } \\
\text { Distance }\end{array}$ & $\begin{array}{l}1.0 \\
1.0\end{array}$ & $\begin{array}{l}1.07 \\
1.24\end{array}$ & $\begin{array}{l}1.05 \\
1.14\end{array}$ & $\begin{array}{l}1.06 \\
1.06\end{array}$ \\
\hline $\begin{array}{l}\text { Standards Presented } \\
\text { Below Eye Level }\end{array}$ & $\begin{array}{l}\text { Size } \\
\text { Distance }\end{array}$ & $\begin{array}{l}1.0 \\
1.0\end{array}$ & $\begin{array}{l}1.27 \\
1.48\end{array}$ & $\begin{array}{l}1.35 \\
1.57\end{array}$ & $\begin{array}{l}1.37 \\
1.66\end{array}$ \\
\hline $\begin{array}{l}\text { Standards Centered } \\
\text { at Eye Level }\end{array}$ & $\begin{array}{l}\text { cular Obs } \\
\text { Size } \\
\text { Distance }\end{array}$ & $\begin{array}{l}\text { tion } \\
1.0 \\
1.0\end{array}$ & $\begin{array}{l}1.33 \\
1.62\end{array}$ & $\begin{array}{l}1.47 \\
1.90\end{array}$ & $\begin{array}{l}1.54 \\
2.13\end{array}$ \\
\hline $\begin{array}{l}\text { Standards Presented } \\
\text { Below Eye Level }\end{array}$ & $\begin{array}{l}\text { Size } \\
\text { Distance }\end{array}$ & $\begin{array}{l}1.0 \\
1.0\end{array}$ & $\begin{array}{l}1.52 \\
2.23\end{array}$ & $\begin{array}{l}1.80 \\
2.90\end{array}$ & $\begin{array}{l}1.86 \\
3.51\end{array}$ \\
\hline
\end{tabular}

that when the standard stimuli were centered at about eye level and viewed monocularly, variations in the distance of the standard had essentially no effect on either the size or the distance estimates. While the objective size and distance of the standard increased fourfold (from the 5- to 20 - $\mathrm{ft}$ location), the judgments of both size and distance increased by only $6 \%$. In addition, the subjects' responses to size and distance did not differ significantly at each setting of the standard.

Lowering the standard stimulus toward the floor improved both the size and the distance judgments, even monocularly. Simple effects showed that the estimates of size increased significantly as a function of the distance of the standard $[F(3,432)=5.59, p<.05]$. NewmanKeuls tests indicated that the primary increase was in response to the $10-\mathrm{ft}$-distant standard $(\mathrm{p}<.01)$, which was judged to be $27 \%$ larger than the 5 -ft-distant one. There were no significant changes thereafter.

The distance judgments also increased significantly as a function of the distance of the standard $[F(3,432)=$ $16.73, p<.01]$. Just as with size, the primary improvement in the estimation of distance was for the 10 -ft-distant target, which was judged to be $48 \%$ further away than the 5-ft-distant one. According to the Newman-Keuls test, this difference was significant $(\mathrm{p}<.01)$. The estimate increases observed for the more distant targets were not significant. Thus, both size and distance perception were positively affected monocularly by adding perspective cues through lowering the position of the standard stimuli.

With regard to the size estimates, the estimates of the lowered targets were significantly higher than those of the central ones at the 15 -ft position $[\mathrm{F}(1,576)=3.93$, $\mathrm{p}<.05]$ and the 20-ft location $[\mathrm{F}(1,576)=4.21$, $\mathrm{p}<.05]$. The same was the case for distance, with the estimates of the lowered stimuli being significantly higher at the $15-\mathrm{ft}[\mathrm{F}(1,576)=8.02, \mathrm{p}<.05]$ and $20-\mathrm{ft}$ $[\mathrm{F}(1,576)=15.37, \mathrm{p}<.01]$ locations.

Although the responses to both size and distance were influenced by vertically varying the position of the standards, they were not affected in equal measure. The lowering of the standards generated a far greater improve- ment in distance perception compared to size at the $10-\mathrm{ft}$ $[\mathrm{F}(1,432)=4.0, \mathrm{p}<.05], 15-\mathrm{ft}[\mathrm{F}(1,432)=4.02$, $\mathrm{p}<.05]$, and $20-\mathrm{ft}[\mathrm{F}(1,432)=6.96, \mathrm{p}<.01]$ locations. These findings can be readily observed merely by inspecting Table 1 . As previously noted, there was a $6 \%$ increment in size from the nearest to the farthest target when the standards were presented centrally. The same was the case for distance. Lowering the standards resulted in only a $37 \%$ increment in apparent size, compared to a $66 \%$ increase in distance perception. It is true that both estimates were poor, even with the targets lowered, for the size and distance judgments should have increased by a factor of four if the subjects had been perceiving veridically. Nonetheless, it is abundantly clear that the limited information that was available pertaining to distance was not being taken fully into account during estimation size.

Both size and distance perception improved with binocular regard. With the standards presented centrally, there was $54 \%$ increment in size from the nearest to the farthest stimulus. This was significant $[F(3,432)=11.22$, $\mathrm{p}<.01]$. According to the Neuman-Keuls test, the primary increase was from $5-10 \mathrm{ft}(\mathrm{p}<.01)$, with no significant changes thereafter.

The distance estimates increased by $113 \%$ from near to far. This increase was significant $[F(3,432)=46.28$, $\mathrm{p}<.01]$. According to the Newman-Keuls test, the distance estimates rose significantly from $5-10 \mathrm{ft}(\mathrm{p}<.01)$, $10-15 \mathrm{ft}(\mathrm{p}<.01)$, and $15-20 \mathrm{ft}(\mathrm{p}<.05)$. These findings indicate that with binocular vision, it became easier to discriminate between distances than between sizes.

The distance estimates were significantly greater (and more accurate) than the size judgments at the $10-\mathrm{ft}$ $[\mathrm{F}(1,432)=6.86, \mathrm{p}<.01], 15-\mathrm{ft}[\mathrm{F}(1,432)=15.99$, $\mathrm{p}<.01]$, and $20-\mathrm{ft}[\mathrm{F}(1,432)=28.28, \mathrm{p}<.01]$ settings of the standard. Thus, it was found once again that the distance cues were not being fully utilized in estimating size.

Lowering the standard stimuli with binocular vision improved the size and distance estimates even more. The size estimates increased at the $15-\mathrm{ft}[\mathrm{F}(1,576)=4.82$, $\mathrm{p}<.05]$ and the $20-\mathrm{ft}[\mathrm{F}(1,576)=4.27, \mathrm{p}<.05]$ settings. The distance judgments increased at the $10-\mathrm{ft}$ $[\mathrm{F}(1,576)=16.23, \mathrm{p}<.01], 15-\mathrm{ft}[\mathrm{F}(1,576)=43.44$, $\mathrm{p}<.01]$, and 20 -ft $[\mathrm{F}(1,576)=82.62, \mathrm{p}<.01]$ locations. Although both the size and the distance judgments were influenced by varying the vertical location of the standard stimuli, they were not affected comparably. The size judgments increased by $81 \%$ from near to far. This was significant $[F(3,432)=5.59, p<.01]$. NewmanKeuls tests showed that the size responses increased from $5-10 \mathrm{ft}(\mathrm{p}<.01)$ and from 10-15 ft ( $\mathrm{p}<.01)$. However, the subjects were unable to discriminate between the sizes of 15 - and 20 -ft-distant stimuli.

In this condition, the distance estimates increased by $251 \%$ from near to far. Reference to Table 1 will show that distance was being perceived almost veridically through $15 \mathrm{ft}$, with some drop at $20 \mathrm{ft}$. Obviously, the 
distance judgments increased significantly from each setting of the standard to the next ( $p<.01$ for each comparison). Just as before, the distance judgments were significantly greater than the size estimates at the $10-\mathrm{ft}$ $[\mathrm{F}(1,432)=41.77, \mathrm{p}<.01], 15-\mathrm{ft}[\mathrm{F}(1,432)=101.66$, $\mathrm{p}<.01]$, and $20-\mathrm{ft}[\mathrm{F}(1,432)=226.19 . \mathrm{p}<.01]$ settings of the standard. Thus, it would appear again that the appreciation of distance did not affect the subjects' estimation of size as much as might have been expected.

The simple effects showed that compared to monocular viewing, the size estimates of the $15-\mathrm{ft}$ - and $20-\mathrm{ft}-$ distant standards increased significantly with binocular vision. This was the case regardless of vertical target position. Similarly, the distance judgments increased significantly with binocular viewing, regardless of target position. However, in this case, significant increments were observed for each setting of the standard. Although both the size and the distance judgments improved with binocular vision, distance perception improved far more than that of size.

"Type of estimate" did not enter into this four-way interaction, indicating that the size and distance judgments were affected comparably by changing the duration of the standard stimulus. Therefore, the size and distance responses were collapsed together for purposes of posttesting. The simple effects revealed that the responses increased significantly as a function of the distance of the standard, at both the $25-\mathrm{msec}[\mathrm{F}(3,216)=49.83$, $\mathrm{p}<.01]$ and $2,000-\mathrm{msec}[\mathrm{F}(3,216)=108.64, \mathrm{p}<.01]$ exposures. Newman-Keuls tests showed that the responses increased significantly from $5-10 \mathrm{ft}(\mathrm{p}<.01)$ for the 25 msec exposure only. At the 2,000-msec exposure, there was a significant response increment from $5-10 \mathrm{ft}, 10$ $15 \mathrm{ft}$, and $15-20 \mathrm{ft}$ ( $\mathrm{p}<.01$ for each comparison).

Although the responses changed as a function of the distance of the standard at both time intervals, the simple effects showed that the responses were significantly greater at the 2,000-msec- than at the 25-msec-exposure interval. This was found for the $10-\mathrm{ft}[\mathrm{F}(1,288)=4.39$, $\mathrm{p}<.05], 15-\mathrm{ft}[\mathrm{F}(1,288)=7.63, \mathrm{p}<.01]$, and the 20 ft $[F(1,288)=13.54, p<.01]$ distant stimuli. Therefore, it would appear that lengthening exposure to the standard stimulus effected an improvement in responding, and this improvement increased with the distance of the standard. This finding facilitates an understanding as to why dynamic size constancy is poor, but it does not suggest that apparent size is the outcome of a process whereby perceived distance is taken into account. Quite to the contrary, our assessment of the significant four-way interaction has shown clearly that perceived size and distance are independent phenomena.

\section{REFERENCES}

Brosgole, L., McNichol, D. G., Doyle, J., \& Neylon, A. (1976) Dynamic size constancy. Bulletin of the Psychonomic Society, 7, 12-14. GREGORY, R. L., \& Ross, H. E. (1964a). Visual constancy during movement: 1 . Effects of S's forward and backward movement on size constancy. Perceptual \& Motor Skills, 18, 3-8.

GREGoRY, R. L., \& Ross, H. E. (1964b). Visual constancy during movement: 2 . Size constancy using one or both eyes or proprioceptive information. Perceptual \& Motor Skills, 18, 23-26.

(Manuscript received for publication August 12, 1985.) 